\title{
Evidence for Decoupled Electron and Proton Transfer in the Electrochemical Oxidation of Ammonia on Pt(100)
}

\author{
Ioannis Katsounaros, ${ }^{*}, 1,2,3$ Ting Chen, ${ }^{3,4}$ Andrew A. Gewirth, ${ }^{1}$ Nenad M. Markovic, ${ }^{2}$ and \\ Marc T. M. Koper ${ }^{*}, 3$ \\ ${ }^{1}$ University of Illinois at Urbana-Champaign, Department of Chemistry, 600 S Mathews Ave, \\ Urbana, IL 61801, United States \\ ${ }^{2}$ Argonne National Laboratory, Materials Science Division, 9700 S Cass Ave, Lemont, IL 60439, \\ United States \\ ${ }^{3}$ Leiden University, Leiden Institute of Chemistry, Einsteinweg 55, P.O. Box 9502, 2300RA \\ Leiden, The Netherlands \\ ${ }^{4}$ School of Science, Shandong Jianzhu University, 250101 Jinan, P.R.China
}

\section{E-mails for correspondence:}

i.katsounaros@lic.leidenuniv.nl (I. Katsounaros); m.koper@chem.leidenuniv.nl (M.T.M. Koper) 


\section{A. Dependence of the pre-peak on the concentration of ammonia}

Figure S1 shows the dependence of the peak potential for the pre-peak versus the activity of ammonia in $0.1 \mathrm{M} \mathrm{KOH}$ solutions, obtained from the positive-direction of the corresponding voltammograms (shown in the inset, shifted for clarity). The position of the pre-peak shifts negatively by around $30 \mathrm{mV}$ for an increase in the concentration of ammonia by one order of magnitude.

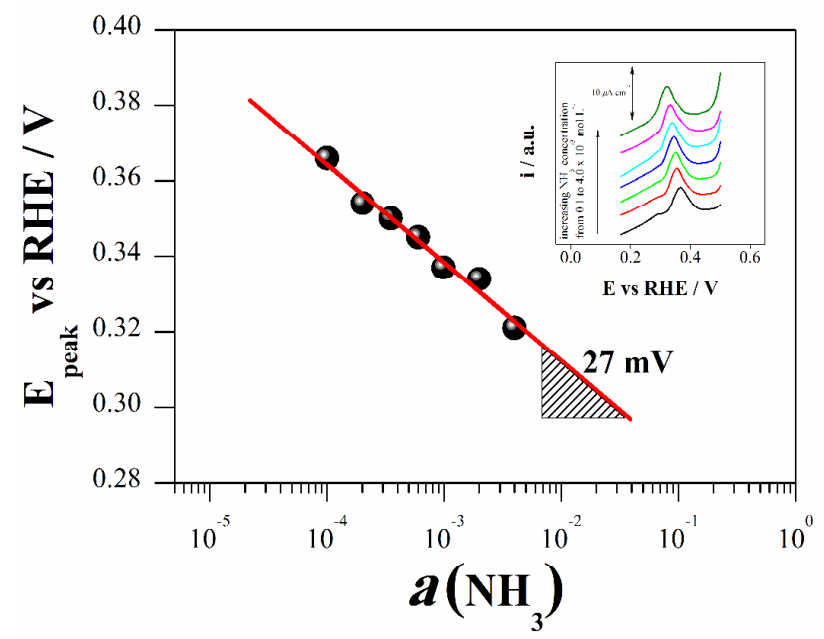

Figure S1. Peak potential for the pre-peak as a function of the activity of ammonia in solution, obtained from the positive direction of cyclic voltammograms with ammonia concentrations in the region 0.1 to 4.0 $10^{-3} \mathrm{M} \mathrm{NH}_{4} \mathrm{ClO}_{4}$ in $0.1 \mathrm{M} \mathrm{KOH}$ (see inset). Scan rate: $0.002 \mathrm{~V} \mathrm{~s}^{-1}$.

\section{B. Calculation of the local pH}

To derive the relationship between the current density and the local $\mathrm{pH}$, we followed the methodology presented in ref. 1. In particular, we take into account the following equilibria:

$$
\begin{array}{ll}
\mathrm{H}_{2} \mathrm{O} \rightleftharpoons \mathrm{H}^{+}+\mathrm{OH}^{-} \quad, \quad \mathrm{K}_{\mathrm{w}}=\mathrm{C}_{\mathrm{H}^{+}} \cdot \mathrm{C}_{\mathrm{OH}^{-}}=10^{-8}\left(\mathrm{~mol} \cdot \mathrm{m}^{-3}\right)^{2} \\
\mathrm{NH}_{4}^{+} \rightleftharpoons \mathrm{NH}_{3}+\mathrm{H}^{+} \quad, \quad \mathrm{K}_{\mathrm{S}}=\frac{\mathrm{C}_{\mathrm{NH}_{3}} \cdot \mathrm{C}_{\mathrm{H}^{+}}}{\mathrm{C}_{\mathrm{NH}_{4}^{+}}}=5.7 \cdot 10^{-7} \mathrm{~mol} \cdot \mathrm{m}^{-3}
\end{array}
$$

The current density is proportional to the flux of the species in solution, and given by:

$$
\mathrm{j}=-\mathrm{F} \cdot\left(\mathrm{D}_{\mathrm{H}^{+}} \cdot \nabla \mathrm{C}_{\mathrm{H}^{+}}-\mathrm{D}_{\mathrm{OH}^{-}} \cdot \nabla \mathrm{C}_{\mathrm{OH}^{-}}\right)-\mathrm{F} \cdot\left(\mathrm{D}_{\mathrm{NH}_{4}^{+}} \cdot \nabla \mathrm{C}_{\mathrm{NH}_{4}^{+}}-\mathrm{D}_{\mathrm{NH}_{3}} \cdot \nabla \mathrm{C}_{\mathrm{NH}_{3}}\right)
$$




$$
\begin{aligned}
& =+\frac{\mathrm{F}}{\delta_{\text {eff }}} \cdot\left\{\mathrm{D}_{\mathrm{H}^{+}} \cdot\left(\mathrm{C}_{\mathrm{H}^{+}}^{\text {surf }}-\mathrm{C}_{\mathrm{H}^{+}}^{\text {bulk }}\right)-\mathrm{D}_{\mathrm{OH}^{+}} \cdot \mathrm{K}_{\mathrm{W}} \cdot\left(\frac{1}{\mathrm{C}_{\mathrm{H}^{+}}^{\text {surf }}}-\frac{1}{\mathrm{C}_{\mathrm{H}^{+}}^{\text {bulk }}}\right)\right\}+\frac{\mathrm{C}_{\mathrm{NH}_{4} \mathrm{ClO}_{4}} \cdot \mathrm{F}}{\delta_{\text {eff }}} \cdot \\
& \cdot\left\{\frac{\mathrm{D}_{\mathrm{NH}_{4}^{+}} \cdot \mathrm{C}_{\mathrm{H}^{+}}^{\text {surf }}-\mathrm{D}_{\mathrm{NH}_{3}} \cdot \mathrm{K}_{\mathrm{S}}}{\mathrm{K}_{\mathrm{S}}+\mathrm{C}_{\mathrm{H}^{+}}^{\text {surf }}}-\frac{\mathrm{D}_{\mathrm{NH}_{4}^{+}} \cdot \mathrm{C}_{\mathrm{H}^{+}}^{\text {bulk }}-\mathrm{D}_{\mathrm{NH}_{3}} \cdot \mathrm{K}_{\mathrm{S}}}{\mathrm{K}_{\mathrm{S}}+\mathrm{C}_{\mathrm{H}^{+}}^{\text {bulk }}}\right\}
\end{aligned}
$$

where:

$\mathrm{F}\left[\mathrm{A} \cdot \mathrm{s} \cdot \mathrm{mol}^{-1}\right]=96,485$

$\delta_{\text {eff }}[\mathrm{m}]=\frac{\mathrm{C}_{\mathrm{H}^{+}} \cdot \delta_{\mathrm{H}^{+}}+\mathrm{C}_{\mathrm{OH}^{-}} \cdot \delta_{\mathrm{OH}^{-}}}{\mathrm{C}_{\mathrm{H}^{+}}+\mathrm{C}_{\mathrm{OH}^{-}}}$

$\delta_{\mathrm{OH}^{-}}[\mathrm{m}]=1.6126 \cdot \mathrm{D}_{\mathrm{OH}^{-}}^{1 / 3} \cdot \mathrm{v}^{1 / 6} \cdot \omega^{-1 / 2}$

$\delta_{\mathrm{H}^{+}}[\mathrm{m}]=1.6126 \cdot \mathrm{D}_{\mathrm{H}^{+}}^{1 / 3} \cdot \mathrm{v}^{1 / 6} \cdot \omega^{-1 / 2}$

$\mathrm{D}_{\mathrm{OH}^{-}}\left[\mathrm{m}^{2} \cdot \mathrm{s}^{-1}\right]=5.27 \cdot 10^{-9}$

$\mathrm{D}_{\mathrm{H}^{+}}\left[\mathrm{m}^{2} \cdot \mathrm{s}^{-1}\right]=9.31 \cdot 10^{-9}$

$\mathrm{v}\left[\mathrm{m}^{2} \cdot \mathrm{s}^{-1}\right]=10^{-6}$

$\omega\left[\mathrm{rad} \cdot \mathrm{s}^{-1}\right]=2 \cdot \pi \cdot \mathrm{f}$

$\mathrm{C}_{\mathrm{NH}_{4} \mathrm{ClO}_{4}}\left[\mathrm{~mol} \cdot \mathrm{m}^{-3}\right]=\mathrm{C}_{\mathrm{NH}_{3}}+\mathrm{C}_{\mathrm{NH}_{4}^{+}}$

$\mathrm{f}\left[\mathrm{s}^{-1}\right]$ : rotation frequency

$\mathrm{C}_{\mathrm{H}^{+}}^{\text {surf }}\left[\mathrm{mol} \cdot \mathrm{m}^{-3}\right]:$ surface concentration of $\mathrm{H}^{+}$

$\mathrm{C}_{\mathrm{H}^{+}}^{\text {bulk }}\left[\mathrm{mol} \cdot \mathrm{m}^{-3}\right]$ : bulk solution concentration of $\mathrm{H}^{+}$

The solution of equation (3) for different values of the bulk $\mathrm{pH}$, for a rotation rate of $400 \mathrm{rpm}$ ( $\mathrm{f}=$ $400 / 60 \mathrm{~s}^{-1}$ ) and for a concentration of ammonium perchlorate $\mathrm{C}_{\mathrm{NH}_{4} \mathrm{ClO}_{4}}=1 \mathrm{~mol} \cdot \mathrm{m}^{-3}$ is schematically shown in Figure S2. In particular, the figure shows the value of the interfacial $\mathrm{pH}$ as predicted from equation (3) for different current densities, and indicates that higher current densities would be required to alter the local $\mathrm{pH}$ in the more alkaline solutions. 


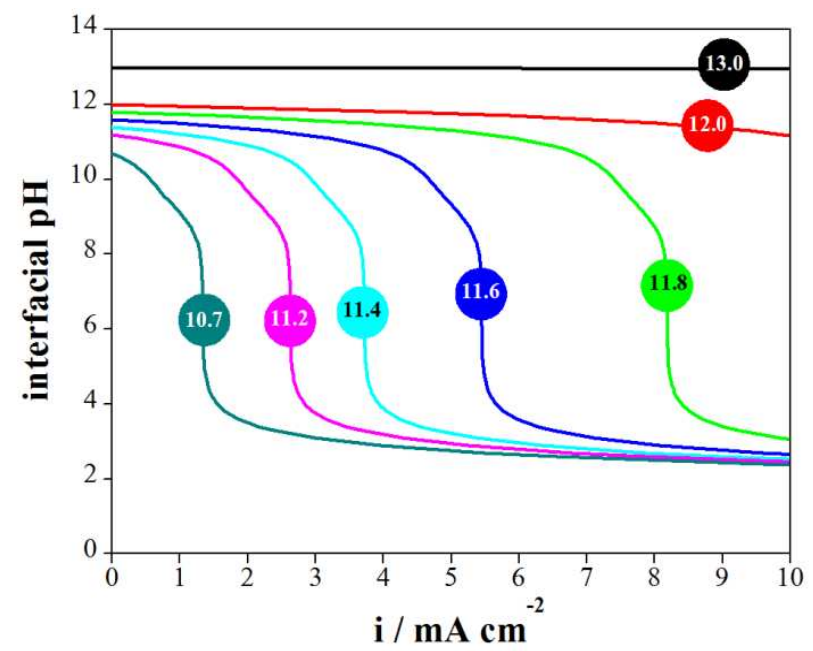

Figure S2. Predicted value of the interfacial $\mathrm{pH}$ as a function of the current density, derived from equation (3) for solutions with different bulk $\mathrm{pH}$ as indicated in the figure. The equation was solved for a rotation rate of $400 \mathrm{rpm}$ and a concentration of ammonium perchlorate of $1 \mathrm{~mol} \mathrm{~m}^{-3}$. The values of the other constants in equation (3) are described in the text.

Considering that the current densities measured under our conditions are not higher than $+1.3 \mathrm{~mA} \mathrm{~cm}^{-2}$, it is evident from Figure $\mathrm{S} 2$ that local $\mathrm{pH}$ changes can become relevant only when the solution $\mathrm{pH}$ is lower than 11.2. For instance, using the experimental data of the measured current density versus the potential for the solution of $\mathrm{pH}=10.7$ and the equation (3), the local $\mathrm{pH}$ at the electrode-electrolyte interface can be calculated versus the potential during the oxidation of ammonia, as shown in Figure S3 (see red curves). The change in the local $\mathrm{pH}$ leads also to a change in the local concentrations of $\mathrm{NH}_{3}$ and $\mathrm{NH}_{4}^{+}$versus the potential due to the equilibrium between this species; their local concentrations can be also calculated using equations (2) and (8) and the calculated local pH for the respective potentials (Figure S3). However, if the solution $\mathrm{pH}$ is 12.3 , then neither the local $\mathrm{pH}$ nor the concentration of $\mathrm{NH}_{3}$ or $\mathrm{NH}_{4}{ }^{+}$changes during the electrochemical reaction, as shown also in Figure S3 (see black curves). It is worth noting that for this solution $\mathrm{pH}$, the equation (3) predicts that a current density as high as $20 \mathrm{~mA}$ $\mathrm{cm}^{-2}$ would be required to alter significantly the interfacial $\mathrm{pH}$ in a solution with bulk $\mathrm{pH}$ of 12.3 , for a rotation rate of $400 \mathrm{rpm}$. 


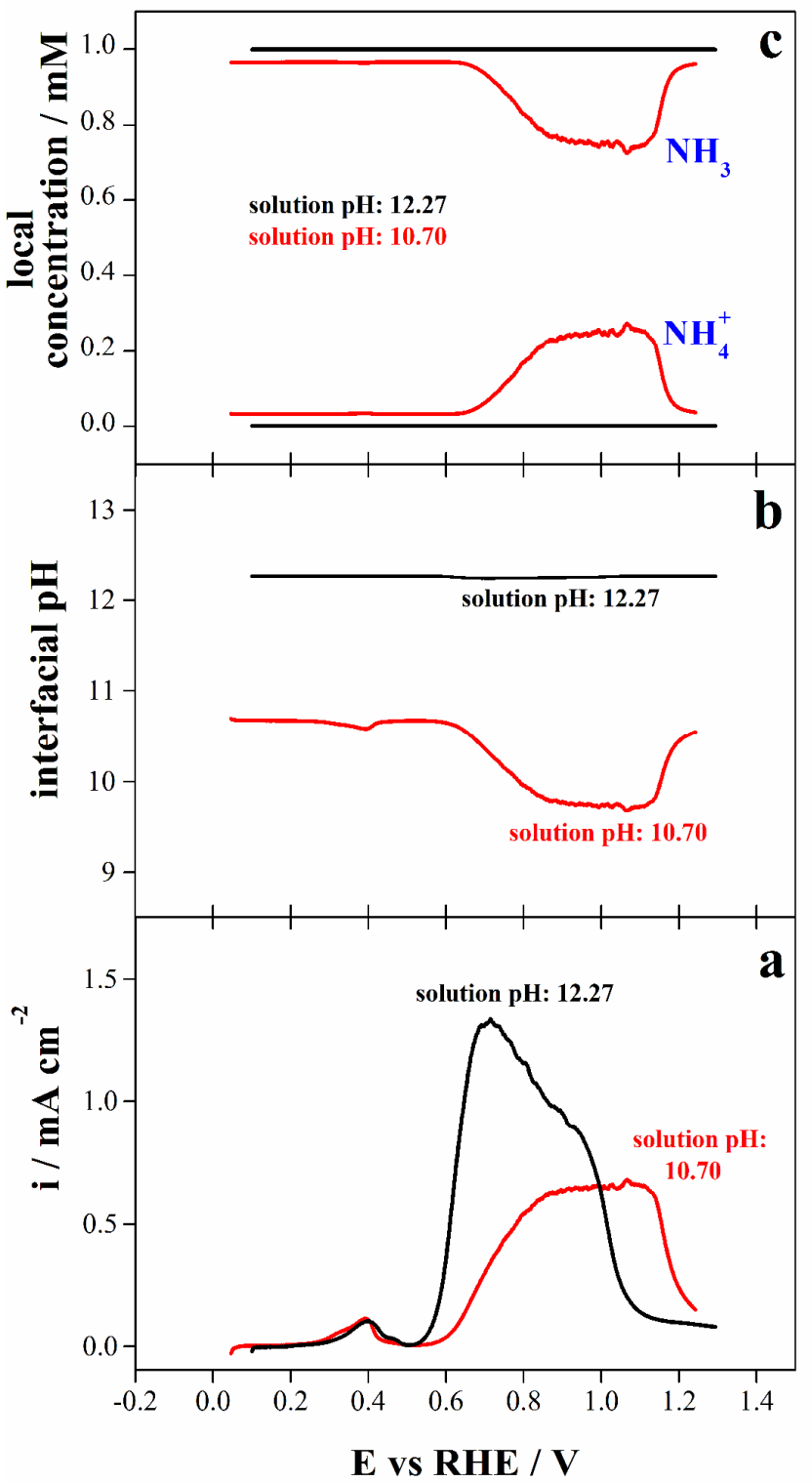

Figure S3. (a): Experimental data during the ammonia oxidation on $\mathrm{Pt}(100)$ in $\mathrm{KOH}$ solutions of different $\mathrm{pH}$ as indicated in the figure and described in detail in the main text; (b): Interfacial $\mathrm{pH}$ as a function of the potential (vs SHE), as predicted from equation (3) using the experimental data shown in (a); (c): Predicted local concentrations of $\mathrm{NH}_{3}$ and $\mathrm{NH}_{4}{ }^{+}$at the solid-liquid interface as a function of the potential, as predicted from equation (3) using the experimental data shown in (a) and the predicted local $\mathrm{pH}$ shown in (b). 
For the above calculations, we made the following assumptions:

- The active sites are not isolated and the oxidation of ammonia as well as the consumption of hydroxide ions takes place homogeneously at the surface. Thus, there are no concentration gradients at any plane parallel to the surface.

- Migration effects were neglected, thus we assumed that mass transport within the diffusion layer is carried out only by diffusion due to concentration gradients.

- Since mass transport in the main solution was carried out by forced convection, we assumed that the concentration at a distance from the electrode equal to the thickness of the diffusion layer (as calculated from Fick's law) is always equal to the concentration of ammonia in the bulk solution.

- Establishment of the equilibria (1) and (2) were considered fast enough to maintain equilibrium conditions for $\mathrm{H}^{+} / \mathrm{OH}^{-}$and for $\mathrm{NH}_{3} / \mathrm{NH}_{4}{ }^{+}$.

- The current density was related to the flux of species (by diffusion) within the diffusion layer, following the Fick's law.

- The sum of the concentrations of $\mathrm{NH}_{3}$ and $\mathrm{NH}_{4}{ }^{+}$was considered constant at any point in the diffusion layer, constant with time, and equal to the initial concentration of $\mathrm{NH}_{4} \mathrm{ClO}_{4}$ dissolved in the $\mathrm{KOH}$ solution.

- Since the diffusion coefficients of $\mathrm{H}^{+}$and $\mathrm{OH}^{-}$are different, a different diffusion layer thickness could be calculated for each species, which would violate the equilibrium (1). For that reason, we assumed an "effective" diffusion layer thickness that corresponds to the weighted average of the two individual diffusion layer thicknesses (equation (4)). See ref. 1 for details.

\section{References}

(1) Auinger, M.; Katsounaros, I.; Meier, J. C.; Klemm, S. O.; Biedermann, P. U.; Topalov, A. A.; Rohwerder, M.; Mayrhofer, K. J. J. Near-Surface Ion Distribution and Buffer Effects during Electrochemical Reactions. Phys. Chem. Chem. Phys. 2011, 13, 16384-16394. 